\title{
Explaining the high working memory capacity of gifted children: Contributions of processing skills and executive control
}

\author{
Alexandre Aubry ${ }^{1}$, Corentin Gonthier ${ }^{2}$ and Béatrice Bourdin ${ }^{1 *}$ \\ ${ }^{1}$ Université de Picardie Jules Verne, CRP-CPO EA 7273, Amiens, France \\ 2 Université Rennes 2, LP3C EA 1285, Rennes, France
}

Warning: This manuscript has not been peer reviewed

* Corresponding author. Béatrice Bourdin, Université de Picardie Jules Verne, CRPCPO EA7273, CS 5250180025 Cedex 1, 1 Chemin du Thil, 80000 Amiens, France. Email: beatrice.bourdin@u-picardie.fr 


\begin{abstract}
Intellectually gifted children tend to demonstrate especially high working memory capacity, an ability that holds a critical role in intellectual functioning. What could explain the differences in working memory performance between intellectually gifted and non-gifted children? We investigated this issue by measuring working memory capacity with complex spans in a sample of 55 gifted and 55 nongifted children. Based on prior studies, we expected the higher working memory capacity of intellectually gifted children to be driven by more effective executive control, as measured with the Attention Network Test. The findings confirmed that intellectually gifted children had higher working memory capacity than typical children, as well as more effective executive attention. Surprisingly, however, working memory differences between groups were not mediated by differences in executive attention. Instead, differences in processing time in the working memory task contributed to the high working memory capacity of gifted children.
\end{abstract}

Keywords: Working memory capacity; Gifted Children; Attention Network Test; Executive attention; Processing time 
Working memory can be viewed as the workspace of cognition, where we briefly store and manipulate information during cognitive activity (Baddeley \& Hitch, 1974). Conceptually, a high working memory capacity is thought to facilitate complex cognitive processing by allowing for the integration of more complex information (Oberauer, Süß, Wilhelm \& Sander, 2008). The role of working memory seems to be important in learning and education in children (see Cowan, 2013 for a discussion), and is an important predictor of academic achievement (Alloway \& Alloway, 2010 ; Gathercole et al., 2004 ; Krumm, Ziegler, \& Buehner, 2008).

Working memory span increases throughout childhood until adolescence, along with cognitive efficiency (Gathercole, Pickering, Ambridge, \& Wearing, 2004; Roberts, Strait, \& Decker, 2018; Thaler et al., 2013). The literature has often reported on the strong relationship withbetween working memory capacity and the development of high-level cognitive activities, such as mathematical processing (see Raghubar, Barnes, \& Hecht, 2010 for a review) and reading comprehension (Daneman \& Carpenter, 1980; Nouwens, Groen, \& Verhoeven, 2016; Seigneuric \& Ehrlich, 2005). Working memory capacity is also strongly related to fluid intelligence (Ackerman, Beier, \& Boyle, 2005), even in children (Giofrè, Mammarella, \& Cornoldi, 2013).

Many studies have shown that intellectually gifted children consistently demonstrate higher working memory capacity than intellectually typical children, (Calero, García-Martín, Jiménez, Kazén, \& Araque, 2007; Hoard, Geary, Byrd-Craven, \& Nugent, 2008; Leikin, Paz-Baruch, \& Leikin, 2013; van Viersen, Kroesbergen, Slot, $\&$ de Bree, 2014). In other words, effective working memory seems characteristic of intellectual giftedness (Hoard et al., 2008; Kornmann, Zettler, Kammerer, Gerjets, \& 
Trautwein, 2015; Vock \& Holling, 2008 ). However, the precise mechanism behind the superior working memory capacity of gifted children is unknown.

What process could lead gifted children to perform higher in working memory tests? While determinants of working memory capacity in the general population are relatively well-known, the correlation between IQ and working memory capacity tends to decrease as intelligence increases (Alloway \& Elsworth, 2012), suggesting that individual differences in working memory capacity may behave differently in gifted children. Besides, gifted children have atypical development, with specific cognitive and non-cognitive characteristics (Corbin, Borel, \& Camos, 2013; Delisle, 1990; Steiner and Carr, 2003), leading to several possible causes for their higher working memory capacity.

In contrast with short-term memory, working memory involves both storage and control mechanisms. This has led some authors to consider that working memory performances issues from the combination of short-form memory and executive attention components (Baddeley, 2000; Barrouillet, Bernardin, \& Camos, 2004; Engle, Tuholski, Laughlin, \& Conway, 1999; Logie, 2011). The executive attention system is essential to inhibit irrelevant information and switch attention between to-beremembered items and concurrent processing (Kane \& Engle, 2003). Executive attention is one of the main determinant of working memory capacity, and a major contributor at its relationship with high-level cognition (McCabe, Roediger, McDaniel, Balota, \& Hambrick, 2010; Unsworth, \& Spillers, 2010). Individual differences in working memory capacity are consistently related to executive attention, both in young adults (e.g. Redick \& Engle, 2006) and in typically developing children (Cowan et al., 2005). In parallel, Intellectually gifted children seem to outperform typical children in 
tasks involving executive attention (Duan, Shi, Wu, Mou, Cui, \& Wang, 2009; Liu, Xiao, Shi, \& Zhao, 2011a, 2011b). These findings suggest that executive attention could explain their high working memory capacity, although to our knowledge no study has evaluated both executive attention and working memory capacity in gifted children.

Although the importance of executive attention for working memory is wellestablished in the literature, other factors influence working memory capacity and could contribute to the higher performance of gifted children. To illustrate these factors, it is necessary to examine the nature of working memory tasks. In psychological research, working memory capacity is usually estimated based on complex span tasks (Conway, Kane, Bunting, Hambrick, Wilhelm, Engle, 2005; Redick et al., 2012). Complex spans require both storage of simple stimuli (such as a letter or a digit) and concurrent processing (such as reading a sentence or solving a simple operation), which directly echoes the definition of working memory. To succeed in such a task, it is necessary to memorize a series of to-be-remembered items as effectively as possible; it is also necessary to perform the concurrent processing tasks as quickly as possible so as to leave time for the refreshing of memory traces.

\section{Objective of The Present Study}

The overarching goal of the current study was to investigate in detail the performance of Intellectually gifted children in complex span tasks and to explore the possible sources of their high working memory spans. Given that executive attention is often regarded as the main determinant of working memory capacity (McCabe, Roediger, McDaniel, Balota, \& Hambrick, 2010) and seems to be more effective in 
gifted children (Duan et al., 2009; Liu et al., 2011a, 2011b), our primary hypothesis was that executive attention would drive the working memory capacity of these children. Because gifted children also demonstrate higher processing speed (Duan et al., 2013), we also examined the effect of processing times on the working memory capacity of these children.

Prior studies of executive attention in gifted children have used specialized experimental paradigms in the context of electrophysiological studies (Duan et al., 2009; Liu et al., 2011a, 2011b). By contrast, we elected to base the present study on the widespread tripartite model of attentional functioning and the corresponding experimental paradigm. Executive attention can be viewed as an attentional network coexisting with two other independent attentional networks (Petersen and Posner, 2012): alerting, defined as achieving an alert state, and orienting, defined as the orientation of attention towards sensory input (Fan, McCandliss, Sommer, Raz, \& Posner, 2002). The Attention Network Test (ANT) was elaborated to assess each attentional network separately (Fan et al., 2002). This task requires the activation of all three attentional networks to respond to simple stimuli while ignoring distractors; it does not require high-level reasoning processes, which makes it well-suited to the comparison of gifted and typical children. While flanker tasks in general (Heitz \& Engle, 2007; Shipstead, Harrison, \& Engle, 2012; Unsworth \& Spillers, 2010) and the ANT in particular (Redick \& Engle, 2006) have demonstrated a relationship with WMC in previous studies, the ANT has never been used in intellectually gifted children to estimate the efficiency of their attentional networks. The current study strived to explore the efficiency of attentional networks as they relate to working memory span in intellectually typical and gifted children. We expected the two groups 
to specifically differ in terms of executive attention performance, not alerting and orienting; we also expected executive attention performance to mediate the difference between the two groups in terms of working memory capacity.

A central aspect of the present study was the method for assessing working memory capacity. Although most working memory tasks are verbal or visuo-spatial in nature, working memory actually constitutes a domain-general construct (Kane, Hambrick, Tuholski, Wilhelm, Payne, \& Engle, 2004). As a consequence, the recommended way to measure working memory capacity is to combine multiple working memory tasks so as to obtain a single score limiting the influence of taskspecific factors (Foster, Shipstead, Harrison, Hicks, Redick, \& Engle, 2014). This approach was adopted in the present study.

Another important point is that prior studies have measured working memory capacity in gifted children using an ascending procedure: participants begin with moderate difficulty trials, the number of to-be-remembered items increases progressively, and the task is cut short when the participant fails a certain number of trials (Hoard, Geary, Byrd-Craven, \& Nugent, 2008; Kornmann, Zettler, Kammerer, Gerjets, \& Trautwein, 2015; van Viersen, Kroesbergen, Slot, \& de Bree, 2014). This ascending order of difficulty poses several problems when assessing the abilities of extreme groups such as intellectually gifted children. High-ability children must succeed on many easy trials before reaching an appropriate level of difficulty. Thus, the ascending order of difficulty can cause fatigue and frustration for high-ability children (e.g. Vandierendonck, De Vooght, \& Van der Goten, 1998). These issues can lead to underestimation of working memory performance in intellectually gifted children. In this type of task, participants with high WMC can fail at the easy trials out of boredom. 
(see Gonthier et al., 2017 for a detailed discussion of these issues). Ceiling effects are also a recurring issue in the context of intellectual giftedness (McCoach, Rambo, \& Welsh, 2012 ; Vock \& Holling, 2008,). To obtain an appropriate measure of working memory capacity, suitable for both typical and gifted children, we developed an adaptive, multimodal complex span task (Gonthier et al., 2017), which was used in the present study.

A final noteworthy aspect of the present study was the criterion for classifying children as gifted. Methods for the identification of intellectually gifted children vary across studies: possible criteria include, for example, high verbal ability scores (Alloway \& Elsworth, 2012; Dark \& Benbow, 1994), nomination by a teacher (Kornmann et al., 2015), or high IQ (Calero et al., 2007; Leikin et al., 2013; van Viersen et al., 2016). These diverse conceptions of giftedness can bias the assessment of cognitive functioning in gifted children. Most conceptions of giftedness are based on the idea of general cognitive ability, operationalized as having a high IQ (McClain \& Pfeiffer, 2012; Warne, 2016). The present study followed this conception, and used intelligence tests to identify children as gifted.

\section{Methods}

\section{Participants}

A sample of 55 intellectually gifted children (mean age $=11.80$ years, $\mathrm{SD}=1.36$, 22 females) and 55 nongifted children (mean age $=11.89$ years, $\mathrm{SD}=1.24$, 22 females) participated in the study. The groups did not significantly differ in terms of age, $t(108)=-0.183, p=.855, d=-0.035$. No children had known learning disorders; all had normal or corrected vision, and all were native French speakers. Participants 
were recruited in elementary and middle schools. The experiment was performed in compliance with local ethics regulations. Signed informed consent was provided by all legal guardians in accordance with the Declaration of Helsinki. Before testing took place, the objectives of the study were explained to the children, who then gave oral agreement for their participation.

The inclusion criterion for children in the gifted group was IQ strictly above 125, corresponding to the 95 th percentile (mean $\mathrm{IQ}=139.64, \mathrm{SD}=8.27$, skewness $=0.08$, kurtosis $=-0.57)$. IQ was estimated with Wechsler Intelligence Scale for Children (WISC-IV; Wechsler, 2005) or with Raven's Standard Progressive Matrices (RSPM; Raven, Raven, \& Court, 1998), in line with current recommendations (Assouline, Foley Nicpon, \& Whiteman, 2009; Aubry \& Bourdin, 2018; McIntosh, Dixon, \& Pierson, 2012). For forty-five children in the gifted group, IQ was estimated with the Wechsler Intelligence Scale for Children (WISC-IV, Wechsler, 2005) by a clinical psychologist in the context of a psychological assessment aiming to identify intellectual giftedness; results of the WISC-IV were unavailable for the remaining ten gifted children, for whom IQ was estimated by RSPM. Children in the nongifted group all had IQ between 85 and $115(\mathrm{M}=103.20, \mathrm{SD}=5.64$, skewness $=-0.09$, kurtosis $=-0.84)$; IQ was estimated with RSPM in all cases.

\section{Measures}

Working Memory. Domain-general working memory capacity was measured with a battery of three computerized complex span tasks, the Adaptative Composite Complex Span (ACCES; Gonthier, Aubry \& Bourdin, 2017). This task has demonstrated adequate psychometric qualities in a sample of 268 French-speaking children (Gonthier et al., 2017). The ACCES is composed of the three most common 
complex span tasks: the reading span, symmetry span, and operation span (Redick et al., 2012). All tasks follow the same structure: participants have to alternate between solving simple problems, and memorizing unrelated stimuli presented after each problem. At the end of each trial, participants are asked to recall all to-be-remembered stimuli in the same order.

The reading span task required participants to decide whether sentences are semantically plausible (e.g. "Les violons font des bulles" / "Violins make bubbles") and to memorize single digits; the symmetry span task required participants to decide whether geometric displays are symmetric and to memorize the location of red squares in a $4 \times 4$ grid; lastly, the operation span task required participant to decide whether simple equations are correct (e.g. $2+3=3$ ) and to memorize consonants chosen to be phonetically distinctive in French. For each complex span task, participants first trained to memorize stimuli, solve problems, and do both tasks at once. They then performed 6 target trials. The number of stimuli to remember varied adaptively as a function of participant performance on the previous trial, with a minimum of 2 and a maximum of 8 (see Gonthier et al., 2017 for details).

Participants performed the reading span, symmetry span and operation span, in order. Working memory span scores were determined for each complex span as the total number of stimuli correctly recalled in the correct position (Conway, Kane, Bunting, Hambrick, Wilhelm, \& Engle, 2005). Scores on the three complex span tasks were standardized and then averaged to produce a single, composite working memory capacity score. Accuracy and median response times on correctly answered processing problems in the three complex span tasks were also retrieved for each participant. To ensure that participants performed both component of the complex spans correctly, the 
data from a subtest were excluded if processing accuracy scores were in the bottom fifth percentile of the sample, and working memory capacity was computed from the other two subtests (Gonthier, Thomassin, \& Roulin, 2015; Unsworth et al., 2005) This occurred for 18 participants ( 3 gifted and 15 nongifted children). No participant failed to meet this processing accuracy threshold on two subtests or more.s

Attentional abilities. The Attention Network Test (ANT; Rueda et al., 2004) was used to estimate the efficiency of three independent attentional networks: alerting, orienting and executive control. The present task was directly based on the classic version of the paradigm (Fan, McCandliss, Sommer, Raz, \& Posner, 2002). The stimuli were fish pointing towards the left or right of the screen (as used in the child version of the ANT ${ }^{1}$ ). Children were required to indicate the direction of target fish by pressing the left or right arrow keys on a keyboard.

The procedure of the ANT is illustrated in Figure 1. Each trial represented one of 12 possible conditions in equal proportion: 4 types of cues (no cue, central cue, double cue or valid spatial cue) x 3 types of targets (congruent, incongruent or neutral). Each trial began with a fixation cross displayed for a random duration (between 400 and $1600 \mathrm{~ms}$ ). One of the four possible cues then appeared for $150 \mathrm{~ms}$. After the disparition of this cue, only the fixation cross was visible for $450 \mathrm{~ms}$. Lastly, a target fish appeared, either alone (neutral condition) or among other fish pointing in the same (congruent condition) or the opposite direction (incongruent condition). Children then had to press the button corresponding to the direction of the target fish within a $1700 \mathrm{~ms}$ delay. The task began with a training phase of 24 trials, including feedback.

1 The stimuli of the task were retrieved from the author website at this address: https:// www.sacklerinstitute.org/cornell/assays_and_tools/ant/jin.fan/ 
Children then performed three experimental blocks of 96 trials without feedback, with a 10 -seconds break between each block.

[Figure 1 near here]

For each participant, average accuracy and median response times were recorded for each condition. Response times were considered only for correct trials; RTs faster than $200 \mathrm{~ms}$ or slower than $1700 \mathrm{~ms}$ were considered as anticipation and omission errors and excluded from the computation (approximately $0.56 \%$ of trials).

The efficiency of overall attentional system was estimated by the proportion of errors and the average of response time in all conditions. Performance of the three attentional networks were then estimated by contrasting performance in two conditions (Fan et al., 2002; Rueda et al., 2004; MacLeod, Lawrence, McConnell, Eskes, Klein, \& Shore, 2010). For the alerting system, average performance in the no cue condition was subtracted from the double cue condition; for the orienting system, the central cue condition was subtracted from the valid cue condition; for the executive control system, the incongruent condition was subtracted from the congruent condition. A linear integrated speed-accuracy score (LISAS; Vandierendonck, 2017) was used to estimated performance in each of the three attentional networks. The LISAS integrates speed and accuracy and provides an accurate representation of cognitive processing; it also tends to be more reliable than either speed or accuracy scores (Hughes, Linck, Bowles, Koeth, \& Bunting, 2013; Vandierendonck, 2017, 2018; Yang, Yang, \& Kang, 2014). In addition, combining speed and accuracy improves the detection of any relationship between working memory capacity and attentional performance (Draheim, 
Hicks, \& Engle, 2016). LISAS were computed with this formula in each condition (Vandierendonck, 2017, 2018):

$L I S A S=R T_{\text {Condition }}+\frac{S D_{R T_{\text {Total }}}}{S D_{P E_{\text {Total }}}} \times P E_{\text {Condition }}$

where $R T_{\text {Condition }}$ and $P E_{\text {Condition }}$ are the mean of median response times and the proportion of errors in a specific condition (i.e. no cue, double cue, spatial cue, central cue, congruent and incongruent trials). $S D_{R T_{T o t a l}}$ and $S D_{P E_{T o t a l}}$ are the overall standard deviation of the response time and the proportion of errors throughout the task. If $S D_{P E_{\text {Total }}}$ or $P E_{\text {Condition }}$ is equal to zero, LISAS corresponds to $R T_{\text {Condition }}$ only (Vandierendonck, 2018).

\section{Procedure}

Participants performed the experiment collectively in two testing sessions. The sessions were separated by no more than one week. During the first session, children performed the ACCES and ANT tasks. The ACCES took on average 35 minutes and the ANT approximately 20 minutes. During the second session, all children whatever the group performed RSPM with a limited time of 30 minutes.

\section{Data Analysis}

The data and R scripts needed to replicate the statistical analyses are available on the Open Science Framework platform at https://osf.io/y48uc/. A first series of analyses examined whether the gifted and nongifted groups differed in terms of overall working memory capacity, processing times and processing accuracy on the working memory task, and in terms of scores for the three attentional networks. These analyses were performed based on the general linear model, using between-subjects ANOVAs and 
mixed-design ANOVAs (with Greenhouse-Geisser correction when appropriate). Posthoc tests were performed using Tukey's HSD. Effects sizes were computed using eta squared and partial eta squared.

A second series of analyses examined whether the difference in working memory capacity between the gifted and nongifted groups was mediated by the processing efficiency and attentional network scores. These analyses were based on bootstrap tests for multiple mediation (Preacher \& Hayes, 2004, 2008). Indirect effects were estimated using the lavaan package (Rosseel, 2012; bias-corrected method with 20000 bootstrap samples). This approach provides 95\% confidence intervals for direct and indirect effects; an effect is significant at the $\mathrm{p}<.05$ level if the $95 \%$ confidence interval does not include zero. Indirect effects were estimated based on all available data (i.e. using the full sample for all putative mediator).

\section{Results}

Descriptive statistics for all measures are summarized in Table 1 and Table 2. All measures in the three complex span tasks had a distribution close of normal, with no indication of ceiling effects in gifted children. Variances were comparable across groups for all measures and Cook's distance did not reveal any outliers in the following analyses.

[Table 1 near here]

[Table 2 near here] 


\section{Comparison between Gifted and Nongifted Children}

\section{Working memory capacity}

Working memory scores for all children in the two groups are displayed in Figure 2. An one-way ANOVA with groups (gifted vs. nongifted) as a factor indicated that intellectually gifted children had significantly higher working memory capacity than nongifted children, $F(1,108)=29.821, \mathrm{MSE}=0.479, p<.001, \eta^{2}=.216$. The advantage of gifted children was equivalent for the three working memory subtests (see Table 1). $82 \%$ of gifted children were above the average of WMC in nongifted children (see Figure 2).

[Figure 2 near here]

\section{Performance on processing problems.}

An one-way ANOVA with group (gifted vs. nongifted) was performed for response times on the processing problems of the ACCES. The main effect of group was significant, indicating that gifted children were overall faster when solving problems in the complex span tasks, $F(1,108)=5.12, \mathrm{MSE}=0.63, p=.025$, $\eta^{2}=0.05$

Likewise, an one-way ANOVA with group (gifted vs. nongifted) was performed for accuracy on the processing problems of the ACCES. The main effect of group was significant, indicating that gifted children were overall more accurate when solving problems in the complex span tasks, $F(1,108)=6.83, \operatorname{MSE}=0.39, p=.010$, $\eta^{2}=0.06$ 


\section{Attentional abilities}

\section{Overall attentional measures}

An one-way ANOVA with groups (gifted vs. nongifted) performed on the overall of the response time and the proportion of errors in all conditions from the ANT. There was no main effect of group on the overall of the response time, $F(1,108)=0.01$, MSE $=7736.77, p=.923, \eta^{2}<0.01$, but gifted children did significantly fewer errors than nongifted children (see Table 2), $F(1,108)=4.79, \operatorname{MSE}=9.39, p=.031$, $\eta^{2}=0.04$

\section{Attentional network scores}

We expected gifted children to demonstrate significantly better executive attention performance, but not necessarily better alerting or orienting. This hypothesis was tested with one-way ANOVAs with groups (gifted vs. nongifted) as factor, separately for response times and accuracy. For response times, gifted children were significantly faster in terms of executive attention (see Table 2), as predicted, $F(1,108)=28.24, \mathrm{MSE}=1829.14, p<.01, \eta^{2}=0.21$. Gifted and nongifted children did not differ significantly in terms of alerting, $F(1,108)=2.47$, MSE $=1597.51$, $p=.119, \eta^{2}=0.02$, or orienting, $F(1,108)=0.02, \mathrm{MSE}=1461.14, p=.883, \eta^{2}<0.01$. These results are displayed in Figure 3.

[Figure 3 near here]

\section{Determinants of High WMC in Intellectually Gifted Children}

In the previous series of analyses, we showed that gifted children not only demonstrated higher working memory capacity; they were also more proficient in their 
solving of concurrent processing problems in the working memory tasks, and demonstrated better executive attention, as suggested by the literature. In order to investigate the possible source of the higher working memory capacity of gifted children, the final series of analyses investigated all these potential mediators of group differences. The child's group (intellectually gifted vs. nongifted) was treated as the predictor variable and their composite working memory score as the outcome variable. Performance on processing problems (accuracy and response times), averaged across the three subtests, and executive attention (based on the LISAS) were included as mediators.

Overall, working memory capacity was negatively correlated with response times on concurrent processing tasks and positively correlated with the executive control network performance (see Table 3). The indirect effect of group on working memory capacity through the mediators was highly significant (total indirect effect $=0.720$, standard error $=0.131,95 \%$ CI $[.460, .972])$, confirming that group-related differences in working memory capacity were mediated by the selected measures. The direct effect of group on working memory capacity was still significant when controlling for the mediators (direct effect $=0.483$, standard error $=0.133,95 \%$ CI $[.216, .737])$, indicating that the mediators did not account for the full extent of working memory differences between groups (see Figure 4).

[Table 3 near here]

[Table 4 near here] 
Contrary to our hypotheses, executive attention did not mediate group-related differences in working memory capacity (indirect effect $=0.076$, standard error $=0.059,95 \%$ CI $[-.025, .207])$. Instead, the higher working memory capacity of gifted children was partly mediated by their higher efficiency on concurrent problems in the working memory tasks in terms of faster response times (indirect effect $=0.143$, standard error $=0.070,95 \%$ CI $[.021, .294])$, but not in terms of accuracy (indirect effect $=0.018$, standard error $=0.033,95 \%$ CI $[-.054, .082])$.

[Figure 4 near here]

\section{Discussion}

Intellectually gifted children are thought to possess higher working memory capacity than nongifted children. Based on a domain-general battery of complex span tasks, in line with best practices from the field of working memory research, our findings confirmed that this is indeed the case. These results replicated prior findings about superior working memory performance in intellectual giftedness (Calero et al., 2007; Hoard et al., 2008; Leikin et al., 2013; van Viersen et al., 2014).

This working memory advantage is important in modern conceptions of intellectual giftedness (Kornmann et al., 2015). However, it is often difficult to measure the working memory in extremes groups such as intellectually gifted children. Experimental studies of working memory based on classic tasks tend to encounter issues (Vock \& Holling, 2008). The use of an adaptive working memory task avoided such a ceiling effect in the present results. Anecdotally, at the end of the testing session, 
children from both groups indicated that the task was moderately difficult in their subjective reports. The use of a domain-general task also confirmed that the higher working memory capacity of gifted children is not restricted to the verbal domain, which is the domain mostly assessed by classic measures.

More generally, these results are in line with the well-documented relationship between intellectual abilities and working memory capacity (e.g. Ackerman, Beier, \& Boyle, 2005; Conway, Cowan, Bunting, Therriault, \& Minkoff, 2002). In other words, the data suggested that the higher intelligence of gifted children was directly related to their high working memory capacity. Overall, these results are compatible with the idea that working memory capacity is strongly related to intellectual functioning. Indeed, $82 \%$ intellectually gifted children of our sample had a WMC superior at the average of nongifted children. The aim of this current study was to explore the potential determinants of their working memory advantage such as executive attention.

Gifted children did globally fewer errors than nongifted children, but both groups had similar global time responses. In local processing level, only the efficiency of executive attention seemed to distinguish both groups: intellectually gifted children were similar in terms of alerting and orienting, but they had higher executive control network performance than their counterparts. However, executive attention did not mediate the higher performance of these children in working memory tasks. Thus, we showed a co-occurrence between an efficient executive attention system and a high working memory span in intellectually gifted children. This conclusion is directly opposite to the prediction we had made for the study, and unexpected given previous studies showing a strong relationship between executive attention and WMC (Heitz \& Engle, 2007; Redick \& Engle, 2006; Shipstead, Harrison, \& Engle, 2012; Unsworth \& 
Spillers, 20106). On the other hand, not all previous studies have found this relationship (Friedman \& Miyake, 2004; Liefooghe, Barrouillet, Vandierendonck, \& Camos, 2008n), and executive attention is not the sole determinant of WMC performance (Bailey, Dunlosky \& Kane, 2011; Dunlosky \& Kane, 2007). Our findings reinforce the idea that executive attention is not always a primary driver of individual differences in working memory.

Among the potential investigated determinants of WMC, only response time in the concurrent processing partially mediate the higher performance of intellectually gifted children in the working memory task. Our results shown than gifted children performed better and faster the problems in the concurrent processing from the working memory task. In other words, gifted children responded quickly to problems in the interference phase of the working memory task without neglecting accuracy. Thus, time processing mediates partially the relationship between WMC and intelligence (Fry \& Hale, 1996; Unsworth, Redick, Heitz, Broadway, \& Engle, 2009). Based on the present data, time processing in the interference phase seems to be involved in the increase of the recall score (Maehara \& Saito, 2007; Towse, Hitch, \& Hutton, 1998). The speed of gifted children in the concurrent processing allows them to refresh their memory traces faster, increasing their performance in working memory (Vergauwe, Camos, \& Barrouillet, 2014). However, our findings cannot know us the nature of this refreshing of memory traces. Indeed, the maintain of information can be explained by the nonattentional processes as effective strategies used (Bailey, Dunlosky, \& Kane, 2011; Coyle, Read, Gaultney, \& Bjorklund, 1998; Harnishfeger \& Bjorklund, 19941) and / or a high rehearsal rate of to-be-remembered items (Fry \& Hale, 2000). These factors could explain the advantage of WMC in gifted children 
(Engle, Tuholski, Laughlin, \& Conway, 1999). One of possible interpretations might be gifted children solve problems rapidly in interference phase to release more time to rehearse the to-be-remembered items. They used not necessarily the strategies more effective than nongifted children (Gaultney, Bjorklund, \& Goldstein, 1996; Harnishfeger \& Bjorklund, 1994). They are more flexible and stable in strategy use than counterparts (Coyle, Read, Gaultney, \& Bjorklund, 1998). In other words, they would adapt the mnemonic strategy according to the effortful of the situation. They would keep the mnemonic strategy known as effective as soon as the first trials (Gaultney et al., 1996). So, their high WMC can be in relation to expend less mental effort to achieve the same cognitive processing as nongifted children in the working memory task.

\section{Limitations of our study}

Our study was mainly focused on one of several profile of giftedness (see Castejón, Gilar, Miñano, \& González, 2016 for details). Indeed, some type of giftedness can have some specific characteristic about the working memory tasks (Benbow \& Minor, 1990; Dark \& Benbow, 19940). Moreover, some intellectually gifted children can be underachieving. These children demonstrate a large discrepancy between their high intellectual potential and their academic achievements (Reis \& McCoach, 2000). In our sample, all intellectually gifted children were already identified, partly due to having the very good school grades. So, our findings are limited to intellectually gifted children with no academic difficulties.

The ANT has the advantage of being a quick assessment of attentional networks performance. This task uses stimuli (i.e. flankers and cues) which need low-cost 
cognitive processing. However, our version of ANT has some limitations (Casteljas et al., 2003; Ishigami, \& Klein, 2010). The alerting and orienting networks performance were both estimated by cue condition (i.e. no and double cue for alerting; center and spatial cues for orienting). The condition specifically dedicated at the estimation of the alerting and orienting networks performance could improve the measure of each attentional networks (Ishigami, \& Klein, 2010). In addition, the ANT was often perceived as long and boring by the children (Ishigami \& Klein, 2015). Although we had few omission errors, this boring aspect of this task can have an impact on children's motivation and on the accuracy of attentional measures.

\section{Conclusion}

Intellectually gifted children are usually identified with a standardized intellectual test. The intellectual capacities are known to strongly linked with working memory capacity (Ackerman et al., 2005). However, the relationship between different cognitive aptitudes is weaker in high IQ children (Rowe et al., 2014) probably in relation to the Spearman's Law of Diminishing Return (Blum \& Holling, 2017). Otherwise, gifted children have an atypical cognitive development viewed as asynchronous development (Corbin, Borel, \& Camos, 2013; Delisle, 1990). In other words, intellectually gifted children are not advanced in the same way across all cognitive domains. The aim of this current study is to investigate this relationship between the working memory capacity and intellectual giftedness. In our sample, our findings showed the working memory capacity is important for the intellectual giftedness. However, working memory assessment cannot be viewed directly as a tool for the identification of intellectual giftedness, but it can be used to extend classic 
intellectual scales such as the WISC. Our results suggest that high working memory capacity is relatively common among gifted children. Assessing cognitive features related to intelligence, beyond IQ itself, also has the advantage of offering a better and more complete understanding of the cognitive profile of each child and its specificities (Acar, Sen, \& Cayirdag, 2016, Cao, Jung, \& Lee, 2017), paving the way for better individual support.

The aim of the current study is the investigation of the determinants of working memory in intellectually gifted children. Surprisingly, their high working memory seems not to be mediated by their high executive control performance, but only to their faster processing on the interference phase in the working memory task. This result indicates the nonattentional processes would be involve in their high WMC. Future studies may investigate the factors in relation to the refreshment of maintained informations in working memory such as metacognitive knowledge or strategy use.

\section{Disclosure statement}

No conflict of interest was reported by the authors.

\section{Funding}

This research was supported by the Regional Council of Hauts de France and the European Regional Development Fund (ERDF).

\section{Acknowledgements}

The authors also thank the children who participated in the study and their families, as well as the elementary and middle schools which authorized the study. The 
authors heartily thank Florence Pâris, Barbara Martin, Jean-Pierre Carron and the Académie de Versailles for their precious help to realize this study.

\section{References}

Acar, S., Sen, S., \& Cayirdag, N. (2016). Consistency of the Performance and Nonperformance Methods in Gifted Identification. Gifted Child Quarterly, 60(2), 81-101. doi:10.1177/0016986216634438

Ackerman, P. L., Beier, M. E., \& Boyle, M. O. (2005). Working Memory and Intelligence: The Same or Different Constructs? Psychological Bulletin, 131(1), 30-60. doi:10.1037/0033-2909.131.1.30

Alloway, T. P., \& Elsworth, M. (2012). An investigation of cognitive skills and behavior in high ability students. Learning and Individual Differences, 22(6), 891-895. doi:10.1016/j.lindif.2012.02.001

Assouline, S. G., Foley Nicpon, M., \& Whiteman, C. (2009). Cognitive and Psychosocial Characteristics of Gifted Students With Written Language Disability. Gifted Child Quarterly, 54(2), 102-115. doi: $10.1177 / 0016986209355974$

Baddeley, A. (2000). The episodic buffer: a new component of working memory? Trends in Cognitive Sciences, 4(11), 417-423. doi:10.1016/ S1364-6613(00)01538-2

Bailey, H., Dunlosky, J., \& Kane, M. J. (2011). Contribution of strategy use to performance on complex and simple span tasks. Memory \& Cognition, 39(3), 447-461. doi:10.3758/s13421-010-0034-3 
Barrouillet, P., Bernardin, S., \& Camos, V. (2004). Time Constraints and Resource Sharing in Adults' Working Memory Spans. Journal of Experimental Psychology: General, 133(1), 83-100. doi:10.1037/0096-3445.133.1.83

Benbow, C. P., \& Minor, L. L. (1990). Cognitive Profiles of Verbally and Mathematically Precocious Students: Implications for Identification of the Gifted. Gifted Child Quarterly, 34(1), 21-26. doi:10.1177/001698629003400105

Blanca, M. J., Alarcón, R., Arnau, J., Bono, R., \& Bendayan, R. (2017). Effect of variance ratio on ANOVA robustness: Might 1.5 be the limit? Behavior Research Methods, 19(59), 1-26. doi:10.3758/s13428-017-0918-2

Cao, T. H., Jung, J. Y., \& Lee, J. (2017). Assessment in Gifted Education: A Review of the Literature From 2005 to 2016. Journal of Advanced Academics, 28(3), 163203. doi:10.1177/1932202X17714572

Callejas, A., Lupiàñez, J., Funes, M. J., \& Tudela, P. (2005). Modulations among the alerting, orienting and executive control networks. Experimental Brain Research, 167(1), 27-37. doi:10.1007/s00221-005-2365-z

Castejón, J. L., Gilar, R., Miñano, P., \& González, M. (2016). Latent class cluster analysis in exploring different profiles of gifted and talented students. Learning and Individual Differences, 50(C), 166-174. doi:10.1016/j.lindif.2016.08.003

Conway, A. R. A., Kane, M. J., Bunting, M. F., Hambrick, D. Z., Wilhelm, O., \& Engle, R. W. (2005). Working memory span tasks: A methodological review and user's guide. Psychonomic Bulletin \& Review, 12(5), 769-786. doi;10.3758/ BF03196772

Conway, A. R. A., Cowan, N., Bunting, M. F., Therriault, D. J., \& Minkoff, S. R. B. (2002). A latent variable analysis of working memory capacity, short-term 
memory capacity, processing speed, and general fluid intelligence. Intelligence, 30(2), 163-183. doi:10.1016/S0160-2896(01)00096-4

Corbin, L., Borel, D., \& Camos, V. (2013). Dissociation mémoire de travail-vitesse de traitement chez les enfants intellectuellement précoces au travers de deux études de cas [Dissociation between working memory and processing speed in gifted children through two case studies]. Enfance, 2012(04), 373-387. doi:10.4074/ S0013754512004028

Coyle, T. R., Read, L. E., Gaultney, J. F., \& Bjorklund, D. F. (1998). Giftedness and variability in strategic processing on a multitrial memory task: Evidence for stability in gifted cognition. Learning and Individual Differences, 10(4), 273290. doi:10.1016/S1041-6080(99)80123-X

Cowan, N. (2013). Working Memory Underpins Cognitive Development, Learning, and Education. Educational Psychology Review, 26(2), 197-223. doi:10.1007/ s10648-013-9246-y

Cowan, N., Elliott, E. M., Scott Saults, J., Morey, C. C., Mattox, S., Hismjatullina, A., \& Conway, A. R. A. (2005). On the capacity of attention: Its estimation and its role in working memory and cognitive aptitudes. Cognitive Psychology, 51(1), 42-100. doi:10.1016/j.cogpsych.2004.12.001

Dark, V. J., \& Benbow, C. P. (1994). Type of stimulus mediates the relationship between working-memory performance and type of precocity. Intelligence, 19(3), 337-357. doi:10.1016/0160-2896(94)90006-X

Delisle, J. R. (1990). The Gifted Adolescent at Risk: Strategies and Resources for Suicide Prevention among Gifted Youth. Journal for the Education of the Gifted, 13(3), 212-228. doi:10.1177/016235329001300303 
Draheim, C., Hicks, K. L., \& Engle, R. W. (2016). Combining Reaction Time and Accuracy. Perspectives on Psychological Science, 11(1), 133-155. doi: $10.1177 / 1745691615596990$

Duan, X., Dan, Z., \& Shi, J. (2013). The Speed of Information Processing of 9- to 13Year-Old Intellectually Gifted Children. Psychological Reports, 112(1), 20-32. doi:10.2466/04.10.49.PR0.112.1.20-32

Duan, X., Shi, J., Wu, J., Mou, Y., Cui, H., \& Wang, G. (2009). Electrophysiological correlates for response inhibition in intellectually gifted children: A Go/NoGo study. Neuroscience Letters, 457(1), 45-48. doi:10.1016/j.neulet.2009.04.006

Dunlosky, J., \& Kane, M. J. (2007). The Contributions of Strategy Use to Working Memory Span: A Comparison of Strategy Assessment Methods. Quarterly Journal of Experimental Psychology, 60(9), 1227-1245. doi: $10.1080 / 17470210600926075$

Engle, R. W., Tuholski, S. W., Laughlin, J. E., \& Conway, A. R. A. (1999). Working memory, short-term memory, and general fluid intelligence: A latent-variable approach. Journal of Experimental Psychology: General, 128(3), 309-331. doi: 10.1037/0096-3445.128.3.309

Fan, J., McCandliss, B. D., Sommer, T., Raz, A., \& Posner, M. I. (2002). Testing the Efficiency and Independence of Attentional Networks. Journal of Cognitive Neuroscience, 14(3), 340-347. doi:10.1162/089892902317361886

Foster, J. L., Shipstead, Z., Harrison, T. L., Hicks, K. L., Redick, T. S., \& Engle, R. W. (2014). Shortened complex span tasks can reliably measure working memory capacity. Memory \& Cognition, 43(2), 226-236. doi:10.3758/s13421-014-0461-7 
Friedman, N. P., \& Miyake, A. (2004). The Relations Among Inhibition and Interference Control Functions: A Latent-Variable Analysis. Journal of Experimental Psychology: General, 133(1), 101-135. doi: $10.1037 / 0096-3445.133 .1 .101$

Gathercole, S. E., Pickering, S. J., Ambridge, B., \& Wearing, H. (2004). The Structure of Working Memory From 4 to 15 Years of Age. Developmental Psychology, 40(2), 177-190. doi:10.1037/0012-1649.40.2.177

Gaultney, J. F., Bjorklund, D. F., \& Goldstein, D. (1996). To Be Young, Gifted, and Strategic: Advantages for Memory Performance. Journal of Experimental Child Psychology, 61(1), 43-66. doi:10.1006/jecp.1996.0002

Giofrè, D., Mammarella, I. C., \& Cornoldi, C. (2013). The structure of working memory and how it relates to intelligence in children. Intelligence, 41(5), 396406. doi:10.1016/j.intell.2013.06.006

Gonthier, C., Aubry, A., \& Bourdin, B. (2017). Measuring working memory capacity in children using adaptive tasks: Example validation of an adaptive complex span. Behavior Research Methods, 27(8), 1-12. doi:10.3758/s13428-017-0916-4

Gonthier, C., Thomassin, N., \& Roulin, J.-L. (2015). The composite complex span: French validation of a short working memory task. Behavior Research Methods, 48(1), 233-242. doi:10.3758/s13428-015-0566-3

Hoard, M. K., Geary, D. C., Byrd-Craven, J., \& Nugent, L. (2008). Mathematical Cognition in Intellectually Precocious First Graders. Developmental Neuropsychology, 33(3), 251-276. doi:10.1080/87565640801982338 
Heitz, R. P., \& Engle, R. W. (2007). Focusing the spotlight: Individual differences in visual attention control. Journal of Experimental Psychology: General, 136(2), 217-240. doi:10.1037/0096-3445.136.2.217

Hughes, M. M., Linck, J. A., Bowles, A. R., Koeth, J. T., \& Bunting, M. F. (2013). Alternatives to switch-cost scoring in the task-switching paradigm: Their reliability and increased validity. Behavior Research Methods, 46(3), 702-721. doi:10.3758/s13428-013-0411-5

Ishigami, Y., \& Klein, R. M. (2015). Repeated Measurement of the Components of Attention With Young Children Using the Attention Network Test: Stability, Isolability, Robustness, and Reliability. Journal of Cognition and Development, 16(1), 144-159. doi:10.1080/15248372.2013.803971

Ishigami, Y., \& Klein, R. M. (2010). Repeated measurement of the components of attention using two versions of the Attention Network Test (ANT): Stability, isolability, robustness, and reliability. Journal of Neuroscience Methods, 190(1), 117-128. doi:10.1016/j.jneumeth.2010.04.019

Kane, M. J., Hambrick, D. Z., Tuholski, S. W., Wilhelm, O., Payne, T. W., \& Engle, R. W. (2004). The Generality of Working Memory Capacity: A Latent-Variable Approach to Verbal and Visuospatial Memory Span and Reasoning. Journal of Experimental Psychology: General, 133(2), 189-217. doi: 10.1037/0096-3445.133.2.189

Kane, M. J., \& Engle, R. W. (2003). Working-memory capacity and the control of attention: The contributions of goal neglect, response competition, and task set to Stroop interference. Journal of Experimental Psychology: General, 132(1), 4770. doi:10.1037/0096-3445.132.1.47 
Kornmann, J., Zettler, I., Kammerer, Y., Gerjets, P., \& Trautwein, U. (2015). What characterizes children nominated as gifted by teachers? A closer consideration of working memory and intelligence. High Ability Studies, 26(1), 75-92. doi: $10.1080 / 13598139.2015 .1033513$

Krumm, S., Ziegler, M., \& Buehner, M. (2008). Reasoning and working memory as predictors of school grades. Learning and Individual Differences, 18(2), 248257. doi:10.1016/j.lindif.2007.08.002

Leikin, M., Paz-Baruch, N., \& Leikin, R. (2013). Memory abilities in generally gifted and excelling-in-mathematics adolescents. Intelligence, 41(5), 566-578. doi: 10.1016/j.intell.2013.07.018

Liefooghe, B., Barrouillet, P., Vandierendonck, A., \& Camos, V. (2008). Working memory costs of task switching. Journal of Experimental Psychology: Learning, Memory, and Cognition, 34(3), 478-494. doi:10.1037/0278-7393.34.3.478

Liu, T., Xiao, T., Shi, J., \& Zhao, D. (2011a). Response preparation and cognitive control of highly intelligent children: a Go-Nogo event-related potential study. Neuroscience, 180(C), 122-128. doi:j.neuroscience.2011.02.022

Liu, T., Xiao, T., Shi, J., \& Zhao, L. (2011b). Sensory gating, inhibition control and child intelligence: an event-related potentials study. Neuroscience, 189(C), 250257. doi:10.1016/j.neuroscience.2011.05.009

Logie, R. H. (2011). The Functional Organization and Capacity Limits of Working Memory. Current Directions in Psychological Science, 20(4), 240-245. doi: $10.1177 / 0963721411415340$ 
Maehara, Y., \& Saito, S. (2007). The relationship between processing and storage in working memory span: Not two sides of the same coin. Journal of Memory and Language, 56(2), 212-228. doi:10.1016/j.jml.2006.07.009

McCabe, D. P., Roediger, H. L., McDaniel, M. A., Balota, D. A., \& Hambrick, D. Z. (2010). The relationship between working memory capacity and executive functioning: Evidence for a common executive attention construct. Neuropsychology, 24(2), 222-243. doi:10.1037/a0017619

McClain, M.-C., \& Pfeiffer, S. (2012). Identification of Gifted Students in the United States Today: A Look at State Definitions, Policies, and Practices. Journal of Applied School Psychology, 28(1), 59-88. doi:10.1080/15377903.2012.643757

McIntosh, D. E., Dixon, F. A., \& Pierson, E. E. (2012). Use of Intelligence Tests in the Identification of Giftedness. In D. P. Flanagan \& P. L. Harrison (Eds.), Contemporary Intellectual Assessment Theories, Tests, and Issues (pp. 623-642). New York, NY.

MacLeod, J. W., Lawrence, M. A., McConnell, M. M., Eskes, G. A., Klein, R. M., \& Shore, D. I. (2010). Appraising the ANT: Psychometric and theoretical considerations of the Attention Network Test. Neuropsychology, 24(5), 637-651. doi:10.1037/a0019803

Nagelkerke, N. J. D. (1991). A Note on a General Definition of the Coefficient of Determination. Biometrika, 78(3), 691-3. doi:10.2307/2337038

Nouwens, S., Groen, M. A., \& Verhoeven, L. (2016). How working memory relates to children's reading comprehension: the importance of domain-specificity in storage and processing. Reading and Writing, 30(1), 105-120. doi:10.1007/ s11145-016-9665-5 
Petersen, S. E., \& Posner, M. I. (2012). The Attention System of the Human Brain: 20 Years After. Annual Review of Neuroscience, 35(1), 73-89. doi:10.1146/annurevneuro-062111-150525

Preacher, K. J., \& Hayes, A. F. (2008). Asymptotic and resampling strategies for assessing and comparing indirect effects in multiple mediator models. Behavior Research Methods, 40(3), 879-891. doi:10.3758/BRM.40.3.879

Preacher, K. J., \& Hayes, A. F. (2004). SPSS and SAS procedures for estimating indirect effects in simple mediation models. Behavior Research Methods, 36(4), 717-731. doi:10.3758/BF03206553

Raghubar, K. P., Barnes, M. A., \& Hecht, S. A. (2010). Working memory and mathematics: A review of developmental, individual difference, and cognitive approaches. Learning and Individual Differences, 20(2), 110-122. doi:10.1016/ j.lindif.2009.10.005

Raven, J., Raven, J. C. \& Court, J. H. (1998). Manual for Raven's Progressive Matrices and Vocabulary Scales. Section 3, The Standard Progressive Matrices. Oxford, England: Oxford Psychologists Press/San Antonio, TX: The Psychological Corporation.

Redick, T. S., Broadway, J. M., Meier, M. E., Kuriakose, P. S., Unsworth, N., Kane, M. J., \& Engle, R. W. (2012). Measuring Working Memory Capacity With Automated Complex Span Tasks. European Journal of Psychological Assessment, 28(3), 164-171. doi:10.1027/1015-5759/a000123

Redick, T. S., \& Engle, R. W. (2006). Working memory capacity and attention network test performance. Applied Cognitive Psychology, 20(5), 713-721. doi:10.1002/ acp. 1224 
Roberts, K. L., Strait, J. A. E., \& Decker, S. L. (2018). Developmental Trajectories of Verbal, Static Visual-Spatial, and Dynamic Visual-Spatial Working Memory. Contemporary School Psychology, 106(1), 1-10. doi:10.1007/s40688-018-0176Z

Rosseel, Y. (2012). lavaan: An R Package for Structural Equation Modeling. Journal of Statistical Software, 48(2), 1-36. doi:10.18637/jss.v048.i02

Rueda, M. R., Fan, J., McCandliss, B. D., Halparin, J. D., Gruber, D. B., Lercari, L. P., \& Posner, M. I. (2004). Development of attentional networks in childhood. Neuropsychologia, 42(8), 1029-1040. doi:10.1016/j.neuropsychologia. 2003.12.012

Seigneuric, A., \& Ehrlich, M.-F. (2005). Contribution of Working Memory Capacity to Children's Reading Comprehension: A Longitudinal Investigation. Reading and Writing, 18(7-9), 617-656. doi:10.1007/s11145-005-2038-0

Shipstead, Z., Harrison, T. L., \& Engle, R. W. (2012). Working Memory Capacity and Visual Attention: Top-Down and Bottom-Up Guidance. Quarterly Journal of Experimental Psychology, 65(3), 401-407. doi:10.1080/17470218.2012.655698

Steiner, H. H., \& Carr, M. (2003). Cognitive Development in Gifted Children: Toward a More Precise Understanding of Emerging Differences in Intelligence. Educational Psychology Review, 15(3), 215-246. doi:10.1023/A:1024636317011 Thaler, N. S., Goldstein, G., Pettegrew, J. W., Luther, J. F., Reynolds, C. R., \& Allen, D. N. (2013). Developmental Aspects of Working and Associative Memory. Archives of Clinical Neuropsychology, 28(4), 348-355. doi:10.1093/arclin/ $\operatorname{acs} 114$ 
Towse, J. N., Hitch, G. J., \& Hutton, U. (1998). A Reevaluation of Working Memory Capacity in Children. Journal of Memory and Language, 39(2), 195-217. doi: 10.1006/jmla.1998.2574

Unsworth, N., \& Spillers, G. J. (2010). Working memory capacity: Attention control, secondary memory, or both? A direct test of the dual-component model. Journal of Memory and Language, 62(4), 392-406. doi:10.1016/j.jml.2010.02.001

Unsworth, N., Redick, T. S., Heitz, R. P., Broadway, J. M., \& Engle, R. W. (2009). Complex working memory span tasks and higher-order cognition: A latentvariable analysis of the relationship between processing and storage. Memory, 17(6), 635-654. doi:10.1080/09658210902998047

Vock, M., \& Holling, H. (2008). The measurement of visuo-spatial and verbalnumerical working memory: Development of IRT-based scales. Intelligence, 36(2), 161-182. doi:10.1016/j.intell.2007.02.004

Vandierendonck, A., De Vooght, G., \& Van der Goten, K. (1998). Does Random Time Interval Generation Interfere with Working Memory Executive Functions? European Journal of Cognitive Psychology, 10(4), 413-442. doi: $10.1080 / 713752284$

Vergauwe, E., Camos, V., \& Barrouillet, P. (2014). The impact of storage on processing: How is information maintained in working memory? Journal of Experimental Psychology: Learning, Memory, and Cognition, 40(4), 1072-1095. doi:10.1037/a0035779

van Viersen, S., Kroesbergen, E. H., Slot, E. M., \& de Bree, E. H. (2014). High Reading Skills Mask Dyslexia in Gifted Children. Journal of Learning Disabilities, 49(2), 189-199. doi:10.1177/0022219414538517 
Warne, R. T. (2015). Five Reasons to Put the gBack Into Giftedness. Gifted Child Quarterly, 60(1), 3-15. doi:10.1177/0016986215605360

Wechsler, D. (2005). Manuel de l'Échelle d'Intelligence de Wechsler pour Enfants-4e édition [Manual for the Wechsler Intelligence Scale for Children-fourth edition]. Paris: Éditions du Centre de Psychologie Appliquée

Yang, H., Yang, S., \& Kang, C. (2014). The relationship between phonological awareness and executive attention in Chinese-English bilingual children. Cognitive Development, 30, 65-80. doi:10.1016/j.cogdev.2013.11.003 


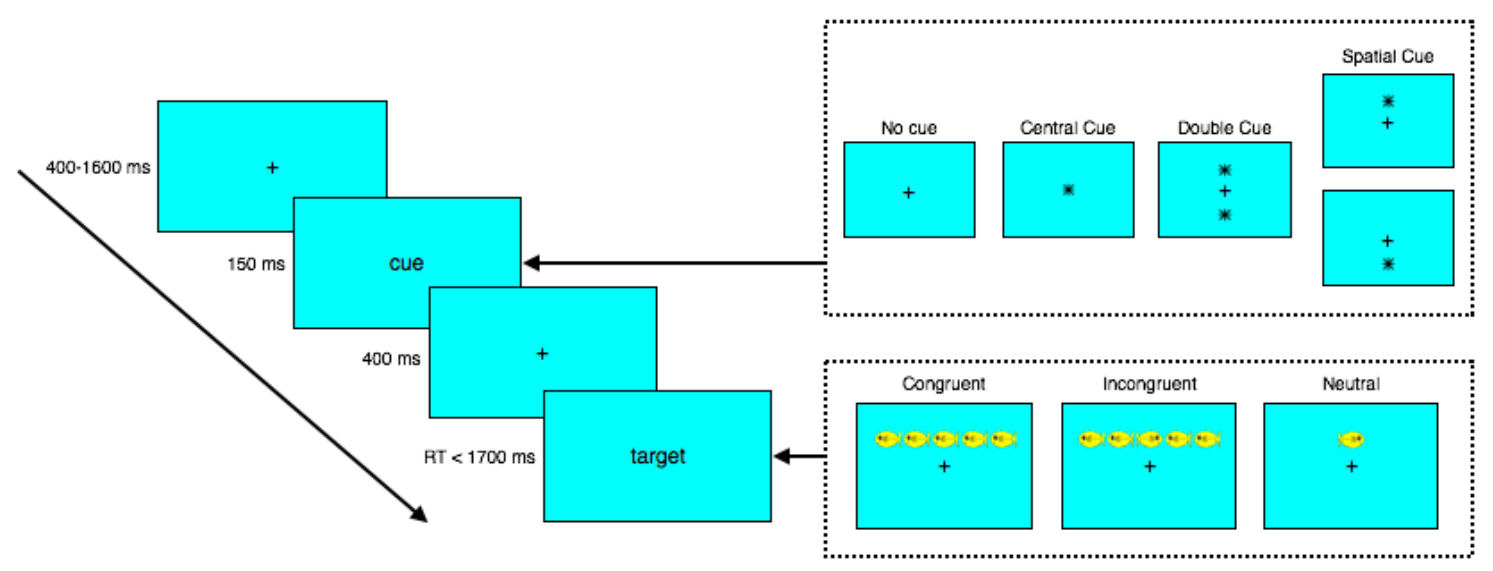

Figure 1. Procedure for the Attention Network Test. 
Table 1. Descriptive statistics for all measures collected in the working memory task as a function of group.

\begin{tabular}{|c|c|c|c|c|c|c|c|c|c|}
\hline \multirow{2}{*}{$\begin{array}{l}\text { Type of } \\
\text { measure }\end{array}$} & \multirow{2}{*}{ Subtest } & \multicolumn{4}{|c|}{ Gifted $(n=55)$} & \multicolumn{4}{|c|}{ Nongifted $(n=55)$} \\
\hline & & $M$ & $S D$ & skew & $\begin{array}{c}\text { kurto } \\
\text { sis }\end{array}$ & $M$ & $S D$ & skew & $\begin{array}{c}\text { kurt } \\
\text { osis }\end{array}$ \\
\hline \multirow{4}{*}{$\begin{array}{l}\text { Recall } \\
\text { scores }\end{array}$} & $\begin{array}{l}\text { Reading } \\
\text { span }\end{array}$ & 26.18 & 5.15 & -0.50 & 0.53 & 21.39 & 5.98 & -0.74 & 2.51 \\
\hline & $\begin{array}{l}\text { Symmetry } \\
\text { span }\end{array}$ & 19.64 & 4.42 & -0.05 & -0.64 & 17.20 & 4.06 & 0.14 & -0.64 \\
\hline & $\begin{array}{c}\text { Operation } \\
\text { span }\end{array}$ & 26.27 & 4.43 & -0.54 & 0.50 & 22.52 & 4.46 & -0.47 & 0.63 \\
\hline & $\begin{array}{l}\text { Composite } \\
\text { score }\end{array}$ & 0.34 & 0.67 & -0.42 & 0.18 & -0.38 & 0.71 & -0.21 & -0.78 \\
\hline \multirow{4}{*}{$\begin{array}{l}\text { Accuracy } \\
\text { on } \\
\text { concurrent } \\
\text { processing } \\
\text { tasks (in } \\
\% \text { correct) }\end{array}$} & $\begin{array}{c}\text { Reading } \\
\text { span }\end{array}$ & 0.95 & 0.04 & -0.74 & -0.10 & 0.94 & 0.04 & -0.22 & -0.57 \\
\hline & $\begin{array}{l}\text { Symmetry } \\
\text { span }\end{array}$ & 0.98 & 0.03 & -1.65 & 1.82 & 0.97 & 0.04 & -0.74 & -0.82 \\
\hline & $\begin{array}{c}\text { Operation } \\
\text { span }\end{array}$ & 0.98 & 0.03 & -1.33 & 1.29 & 0.96 & 0.03 & -0.35 & -0.90 \\
\hline & $\begin{array}{c}\text { Average } \\
\text { accuracy } 1\end{array}$ & 0.15 & 0.51 & -0.12 & -0.82 & -0.16 & 0.71 & -0.37 & 0.34 \\
\hline \multirow{4}{*}{$\begin{array}{l}\text { Median } \\
\text { response } \\
\text { time on } \\
\text { concurrent } \\
\text { processing } \\
\text { tasks (in } \\
\text { seconds) }\end{array}$} & $\begin{array}{l}\text { Reading } \\
\text { span }\end{array}$ & 2.57 & 0.65 & 1.23 & 1.75 & 2.90 & 0.65 & 0.64 & 0.05 \\
\hline & $\begin{array}{l}\text { Symmetry } \\
\text { span }\end{array}$ & 2.03 & 0.52 & 0.60 & -0.62 & 2.13 & 0.47 & 0.49 & -0.34 \\
\hline & $\begin{array}{c}\text { Operation } \\
\text { span }\end{array}$ & 2.10 & 0.48 & 0.24 & -0.67 & 2.24 & 0.52 & 0.70 & 0.63 \\
\hline & $\begin{array}{l}\text { Average } \\
\text { response } \\
\text { time } 1\end{array}$ & -0.15 & 0.82 & 0.77 & 0.53 & 0.19 & 0.77 & 0.45 & 0.16 \\
\hline
\end{tabular}

1 The average of each measure on the concurrent processing (responses time or accuracy) transformed on z-score. 
Table 2. Descriptive statistics for all measures collected in the ANT as a function of group.

\begin{tabular}{|c|c|c|c|c|c|c|c|c|}
\hline \multirow{2}{*}{$\begin{array}{c}\text { Attentional } \\
\text { Measure }\end{array}$} & \multicolumn{4}{|c|}{ Gifted $(n=55)$} & \multicolumn{4}{|c|}{ Nongifted $(n=55)$} \\
\hline & $M$ & $S D$ & skew & $\begin{array}{c}\text { kurtos } \\
\text { is }\end{array}$ & $M$ & $S D$ & skew & $\begin{array}{c}\text { kurtos } \\
\text { is } \\
\end{array}$ \\
\hline \multicolumn{9}{|l|}{ Overall } \\
\hline RT (ms) & 639.77 & 97.15 & 0.91 & 1.35 & 638.14 & 77.69 & 0.14 & -0.30 \\
\hline Error Rate & 2.55 & 1.92 & 1.56 & 3.46 & 3.92 & 2.22 & 0.49 & -0.55 \\
\hline \multicolumn{9}{|l|}{ Networks 1} \\
\hline Alerting & 26.49 & 44.77 & -0.01 & -0.15 & 38.46 & 34.50 & 0.03 & 1.15 \\
\hline Orienting & 53.99 & 32.50 & -0.07 & 3.10 & 52.91 & 43.20 & 0.18 & -0.01 \\
\hline $\begin{array}{l}\text { Executive } \\
\text { control }\end{array}$ & 115.56 & 46.27 & -0.01 & -0.26 & 158.90 & 38.95 & 0.18 & -0.74 \\
\hline
\end{tabular}

1 Attentional network scores were calculated based on the LISAS (Vandierendonck, 2017, 2018). Lower LISAS represents better performance at the considered network. 


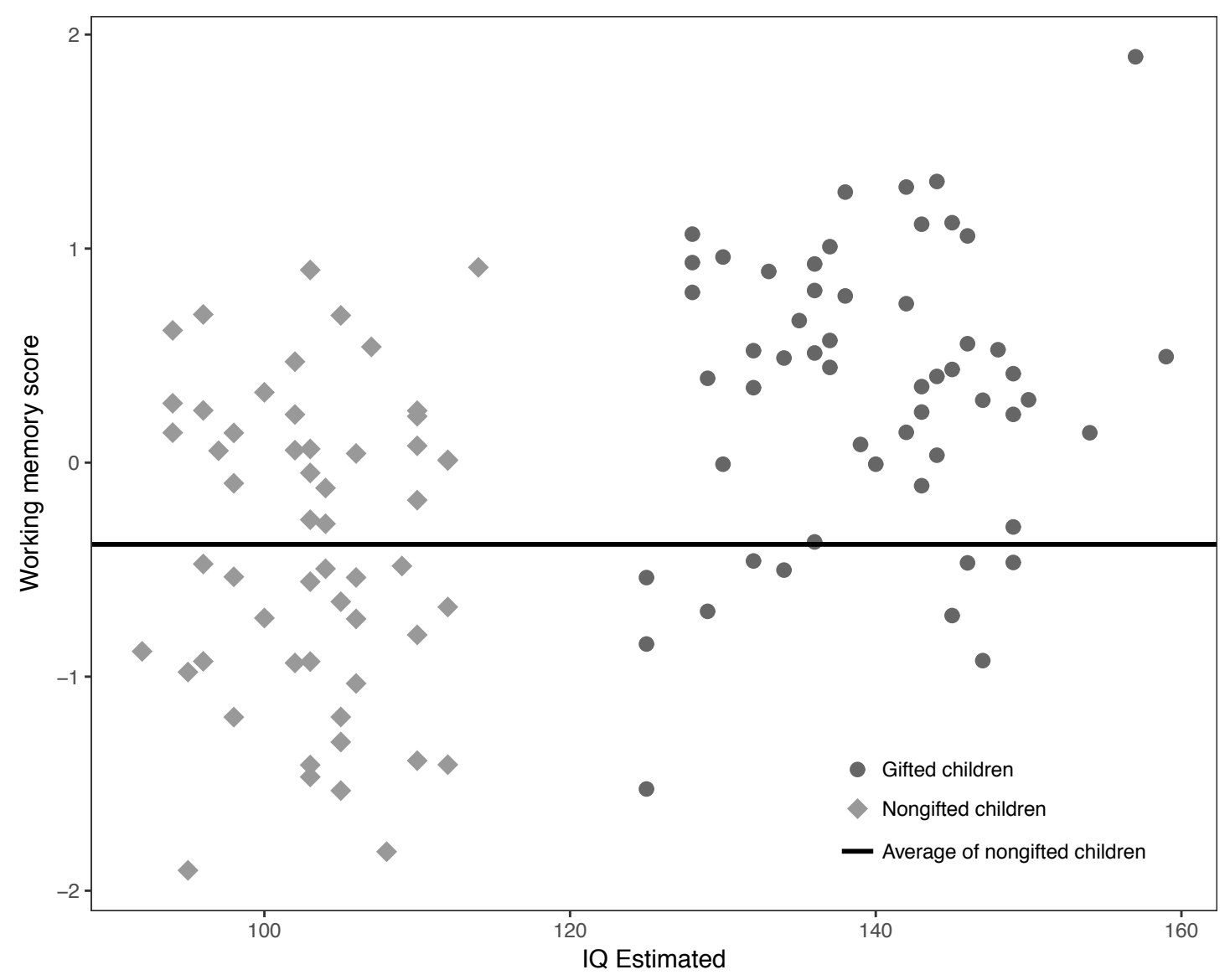

Figure 2. Working memory scores for gifted and nongifted children. 


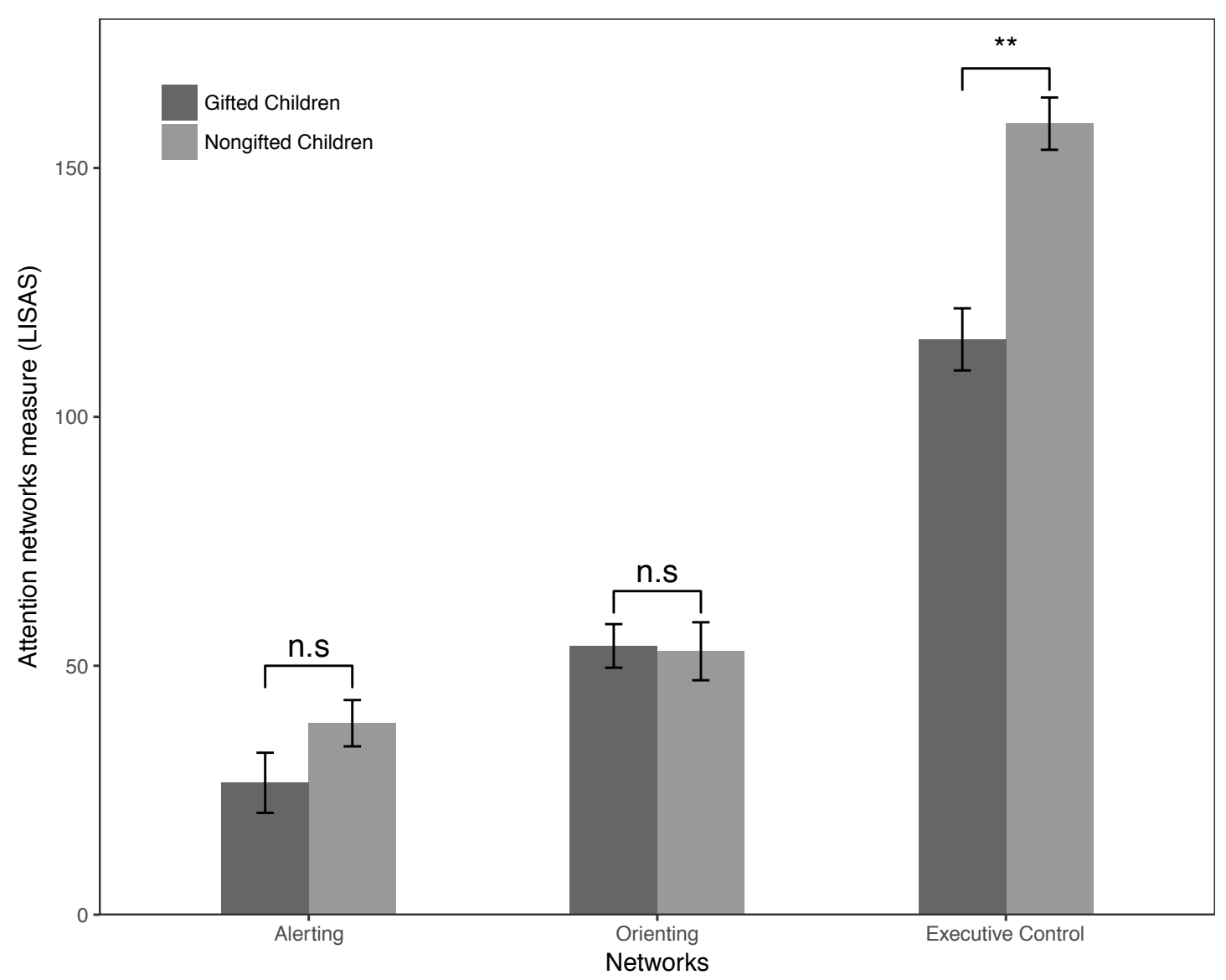

Figure 3. Attentional network scores (based on the LISAS) for gifted and nongifted children. Error bars represent standard errors of the mean. $* * p<.01$ 
Table 3. Bivariate correlations between working memory capacity and possible mediators as a function of group.

\begin{tabular}{lccc}
\hline Measure & $\begin{array}{c}\text { Gifted } \\
\text { children } \\
(n=55)\end{array}$ & $\begin{array}{c}\text { Nongifted } \\
\text { children } \\
(n=55)\end{array}$ & $\begin{array}{c}\text { Whole sample } \\
(N=\mathbf{1 1 0})\end{array}$ \\
\hline $\begin{array}{l}\text { Performance on concurrent } \\
\text { processing tasks: accuracy }\end{array}$ & -.05 & .21 & $\mathbf{. 2 0}$ \\
$\begin{array}{l}\text { Performance on concurrent } \\
\text { processing tasks: response time }\end{array}$ & -.45 & -.51 & $\mathbf{- . 5 2}$ \\
\begin{tabular}{l} 
Executive control \\
\hline
\end{tabular} & -.09 & -.18 & $\mathbf{- . 3 1}$ \\
\hline
\end{tabular}

Note. Significant correlations are in bold. 


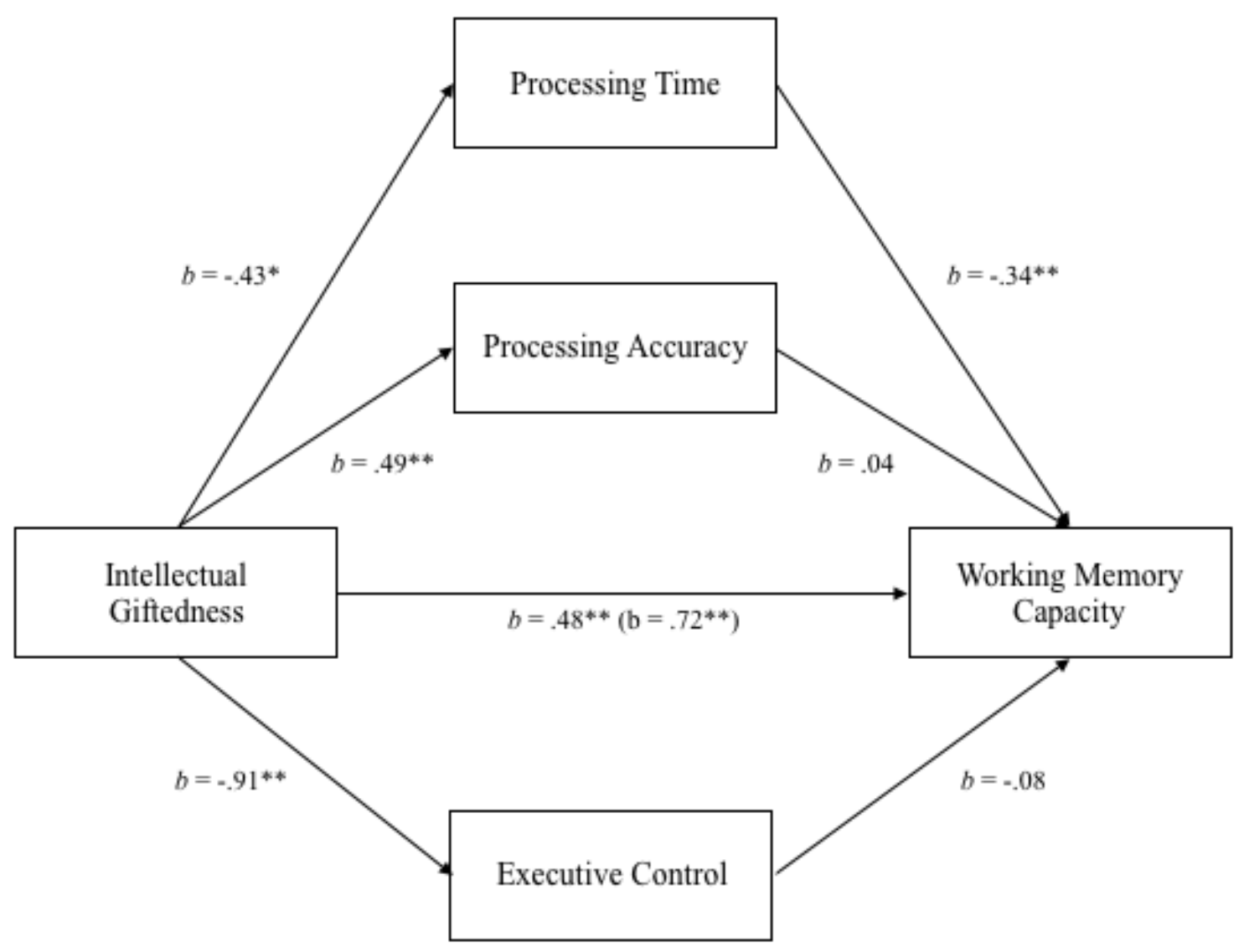

Figure 4. Mediation model showing the association of working memory capacity and intellectual giftedness (gifted vs. nongifted) with the mediating variables (response time and accuracy in the concurrent processing tasks, and executive control network performance). $* p<.05 ; * * p<.01$ 